\title{
Cascading effects from predator removal depend on resource availability in a benthic food web
}

\author{
Katrin Sieben • Anneke D. Rippen • \\ Britas Klemens Eriksson
}

Received: 23 April 2010/ Accepted: 14 October 2010/Published online: 3 November 2010

(C) The Author(s) 2010. This article is published with open access at Springerlink.com

\begin{abstract}
We tested joint effects of predator loss and increased resource availability on the grazers' trophic level and the propagation of trophic interactions in a benthic food web by excluding larger predatory fish from cages and manipulating nutrients in the coastal zone of the Baltic Sea. The combination of nutrient enrichment and excluding larger predators induced an increase in medium-sized predatory fish (three-spined stickleback). The meso-predator fish in turn did not change the total abundance of the invertebrate herbivores, but did cause a substantial shift in their community composition towards the dominance of gastropods by reducing amphipods by $40-60 \%$, while gastropods were left unchanged. The shift in grazer composition generated a 23 times higher producer biomass, but only under nutrient enrichment. Our results show that top-predator declines can substantially shift the species composition at the grazers' level, but that cascading effects on producers by a trophic cascade strongly depend on resource availability.
\end{abstract}

\section{Introduction}

World-wide declines in top-predator communities have altered the structure and dynamics of food webs across

Communicated by F. Bulleri.

K. Sieben $(\varangle) \cdot$ A. D. Rippen · B. K. Eriksson

Department of Marine Benthic Ecology and Evolution,

Centre for Ecological and Evolutionary Studies,

University of Groningen, PO Box 11103,

9700 CC Groningen, The Netherlands

e-mail: k.sieben@rug.nl ecosystems (Myers and Worm 2003; Sala 2006; Heithaus et al. 2008). Declines in large predators may generate community-wide trophic cascades as it was shown for example for lakes (Carpenter et al. 1985) and benthic marine systems (Estes et al. 1998), where increases of medium-sized predators (meso-predator release) induce reciprocal changes in the total abundance of adjacent trophic levels (Pace et al. 1999). However, such examples are limited because most natural ecosystems are not simple food chains with homogenous trophic levels, but rather highly interactive food webs where different trophic levels are composed of species with different functional traits (Steiner 2001; Vasas et al. 2007). Thus, we would predict that changes in predator abundances should affect the species composition instead of the total abundance of prey (Duffy 2002), and that predator identity should determine which prey groups increase or decrease. This predator heterogeneity becomes particularly apparent at higher trophic levels where omnivory and intraguild predation are common, which may dilute effects of single species groups in the food web and weaken trophic cascades (Polis and Holt 1992; Stachowicz et al. 2007).

Trophic cascades are enhanced by ecosystem productivity (Oksanen et al. 1981; Pace et al. 1999), which would suggest that effects of top-predator declines closely interact with another global trend, eutrophication. The effects of nutrient enrichment in food webs in turn depend on the strength of top-down control (Gruner et al. 2008). In systems with strong top-down control we expect nutrient enrichment mainly to increase the abundance of prey species that are resistant to predation. Gruner et al. (2008) referred to this scenario as 'induced resistance'. In systems with weak top-down control, we mainly expect fast-growing prey species to increase from nutrient enrichment ('tolerance'). Nutrient effects on producer 
biomass then depend on different grazer species abilities to utilise and incorporate the increased quantity and quality of their food resource (Hillebrand and Kahlert 2001).

In this study we tested joint effects of removing larger fish and nutrient enrichment on a coastal food web in the Baltic Sea. In the Baltic Sea, local declines of the dominant larger predatory fish Perca fluviatilis L. (European perch) and Esox lucius L. (Northern pike) coincide with soaring abundances of smaller bodied fish, mainly Gasterosteus aculeatus L. (three-spined stickleback), and a resulting enhancement of filamentous algae (Eriksson et al. 2009). In earlier experiments we demonstrated that this is caused by a trophic cascade where a meso-predator release of stickleback increased the growth of filamentous algae by decreasing grazing rates. However, grazer responses to predator exclusion were ambiguous, and no changes in the abundance of grazers that are effective consumers of macroalgae (e.g. amphipods and isopods) were found. Instead, we only detected compositional changes in the invertebrate community that depended on higher bivalve abundances and lower abundances of small gastropods $(<2 \mathrm{~mm})$, of which only the small gastropods could constitute a link between the exclusion of large predators and the enhanced algal biomass production. In this study we therefore focus on the response of the grazer composition to top-down and bottom-up forces with respect to different grazer functional groups, to specifically understand which responses of the grazer community contribute to the documented changes in grazing rates.

At present, perch (carnivore) and stickleback (facultative planktivore) are among the most abundant coastal fishes in the Baltic Sea (Ådjers et al. 2006). Herbivores are dominated by crustacean grazers (amphipods and isopods), which are consumed by both perch and stickleback, and gastropods, which only play a minor role in the diet of perch and are not eaten by stickleback (Lappalainen et al. 2001). Moreover, the grazers have distinctly different feeding strategies: amphipods and isopods are efficient macroalgal grazers while gastropods mainly consume microalgal film (Råberg and Kautsky 2007b). We tested the hypothesis that trophic cascades from declines in top-predators to primary producers depend on both the functional traits of their prey and resource availability, by field manipulations of the coastal fish community and nutrients. Specifically, we hypothesise that removing larger predatory fish generates a meso-predator release of stickleback, that together with nutrient enrichment cascade down the food web to increase the biomass of filamentous macroalgae, by changing the composition of the grazer community towards stronger dominance of gastropods (which are unpalatable to sticklebacks and inefficient grazers on macroalgae).

\section{Methods}

Study system and organisms

The brackish water of the western Baltic Sea is non-tidal and characterised by low species diversity. The coastal fish community consists of both marine and freshwater species. Perca fluviatilis (hereafter perch) and Gasterosteus aculeatus (hereafter stickleback) are among the most abundant fish species in the study area (Eriksson et al. 2009). Perch as a top-predator is strictly carnivorous and undergoes three major dietary shifts during its ontogeny, first feeding on zooplankton, then on macroinvertebrates, and finally on fish (Lappalainen et al. 2001; Kahl and Radke 2006 and references therein). Large perch is therefore mostly piscivorous and feeds on juvenile stages of roach and perch (Eklöv and Persson 1995), and stickleback (pers. obs.), but also on crustaceans (Lappalainen et al. 2001). Stickleback is an important meso-predator in the system, which prefers zooplankton over benthic prey. However, as the availability of zooplankton decreases zoobenthos becomes more important (Ibrahim and Huntingford 1989). Stickleback mainly feeds on copepods, gammarid amphipods, and larvae of Chironomidae (pers. obs.) in the study area.

The experiment was performed in subtidal communities, dominated at the basal level by the seaweed Fucus vesiculosus $\mathrm{L}$. (hereafter Fucus), which provides important habitat for associated filamentous macroalgae (e.g. Cladophora glomerata (L.) Kützing, Pilayella littoralis (L.) Kjellman, and Ulva spp.), and an invertebrate grazer assemblage dominated by amphipods (mainly Gammarus spp., hereafter Gammarus), gastropods (mainly Theodoxus fluviatilis L. and Hydrobia spp., hereafter Theodoxus and Hydrobia), and isopods (mainly Idotea spp. and Jaera albifrons (Leach), hereafter Idotea and Jaera) (Råberg and Kautsky 2007a; Wikström and Kautsky 2007). Theodoxus and Hydrobia are efficient consumers of diatoms and microalgae (Kofoed 1975; Råberg and Kautsky 2007b). Gammarus species are considered selective omnivores, feeding on filamentous macroalgae and larger plant material, as well as fine detritus, other invertebrates and fish eggs (MacNeil et al. 1997; Orav-Kotta and Kotta 2003). Thus, the grazer community is dominated by species of two different feeding groups: (1) 'shredders' (amphipods and isopods) that consume macroalgae and are potential prey for both perch and stickleback, and (2) 'scrapers' (gastropods) that mainly consume benthic microalgae, and that are probably unpalatable to stickleback and only of minor importance to perch. Therefore, we only included amphipods, isopods, and gastropods from the total invertebrate assemblages into our analyses. 
Field experiment

The field experiment was conducted at the Askö Laboratory, western Baltic Sea, Sweden $\left(58^{\circ} 48^{\prime} \mathrm{N}, 17^{\circ} 40^{\prime} \mathrm{E}\right)$. We tested the hypothesis of joint effects of large predatory fish and nutrient enrichment on the grazer and macroalgal community by excluding larger fish and adding agricultural fertiliser.

The experiment was designed as a factorial combination of large predatory fish (open/closed cages) and nutrient enrichment (ambient/enriched) with 5 replicates per treatment (= 20 plots). The experiment ran for 12 weeks from 22 June to 17 September 2007. We placed steel-framed cages $(120 \times 55 \times 100 \mathrm{~cm}$, length $\times$ width $\times$ height $)$, covered with a plastic net (mesh size $1.4 \mathrm{~cm}$ ), in shallow water $(1 \mathrm{~m}$ deep). Partial cages (= 'open') were used to separate cage from predation effects (Steele 1996) and had openings (diagonally half-opened per side) on two nonopposite sides where larger fish could enter (see Figures and Tables in Appendix). The closed cages could only be accessed by small fish (size of sticklebacks) through the mesh. Stickleback access to the cages was examined during snorkelling observations every one to two weeks during the experiment. Perch was frequently observed in the study area but could not be counted per cage, because they disappeared too quickly when disturbed by the snorkelling observations. Coated slow-release N-P-K fertiliser pellets (Plantacote Depot $6 \mathrm{M}$, Urania Agrochem, Hamburg, Germany) were used to continuously enrich the water column with nitrogen $\left(14 \%\right.$, as $\mathrm{NH}_{4}-\mathrm{N}$ and $\left.\mathrm{NH}_{3}-\mathrm{N}\right)$, phosphorus $\left(9 \%\right.$, as $\left.\mathrm{P}_{2} \mathrm{O}_{5}\right)$, and potassium $\left(15 \%\right.$, as $\left.\mathrm{K}_{2} \mathrm{O}\right)$. The fertiliser was supplied from elongated mesh bags $(20 \times 10 \mathrm{~cm}, 1 \mathrm{~mm}$ mesh size, $120 \mathrm{~g}$ per bag, 4 bags per enriched cage) that were placed in two opposite corners and two opposite long sides of the enriched cages. Fertiliser bags were replaced after 6 weeks. This method has already been validated to enrich the water column (Worm et al. 2000) and to subsequently increase producer biomass (Hillebrand and Kahlert 2001). The enrichment resulted in 49-69\% higher levels of total phosphorus (as $\mathrm{PO}_{4}{ }^{3-}$ ), and 105-187\% higher levels of total nitrogen (as $\mathrm{NH}_{4}{ }^{+}, \mathrm{NO}_{3}{ }^{-}$/ $\mathrm{NO}_{2}{ }^{-}$), inside the enriched cages in June and July respectively (ambient nutrient levels: June: total $P=4.17 \pm 0.1346 \mu \mathrm{g} \mathrm{L}^{-1}$, total $N=5.12 \pm 1.0846 \mu \mathrm{g}$ $\mathrm{L}^{-1}$; July: total $P=2.95 \pm 0.2046 \mu \mathrm{g} \mathrm{L}^{-1}$, total $N=3.64 \pm 0.46 \mu \mathrm{g} \mathrm{L}^{-1}$; mean $\pm \mathrm{SE}$; see Figures and Tables in Appendix for statistics). The increase in nutrient concentrations in the enriched plots relative to the ambient levels was half the magnitude of the measured differences between a regularly monitored eutrophied site $20 \mathrm{~km}$ to the north and the oligotrophic study site in summers between 1990 and 2000 (Granéli et al. 1990). Cages were placed at least $3 \mathrm{~m}$ apart from each other to avoid cross-fertilisation and followed a randomized block design. Periphyton was brushed off from the outside of the cages once per week.

Invertebrate communities were collected by using Fucus as a sampling unit. Therefore, bundles of Fucus with no visible epiphytes were collected near the study area prior to the start of the experiment, cleaned from epifauna, and anchored to a brick. One bundle of Fucus $(41.7 \pm 1.4 \mathrm{~g}$ $\mathrm{DW}$, mean $\pm \mathrm{SE}, n=30$ ) was placed inside each cage. In order to control for cage artefacts a no-cage-plot was included by placing one Fucus outside of each open cage for pair-wises comparisons with the according open cages. Invertebrates were sampled by pulling a net bag (mesh size $1 \mathrm{~mm}$ ) over each Fucus bundle, enclosing all of the associated fauna under water. Invertebrates were sampled twice, on 5 July and at the end of the experiment on 17 September. Only the first sample was used in the analyses, as the meso-predator stickleback moved away from the coastal zone in late July (see results), making the predator treatment of little relevance for the mobile invertebrates in September. Animals were sorted under a dissecting microscope, determined to species level if possible, counted, and dried at $60^{\circ} \mathrm{C}$ for at least $48 \mathrm{~h}$ to determine dry weight. Dry weight was converted to ash-free dry weight by using species-specific conversion factors (Lappalainen and Kangas 1975). All invertebrate data were recalculated to abundance and biomass per $100 \mathrm{~g}$ DW of Fucus.

Net production of macroalgae was examined with the use of unglazed ceramic tiles $(5 \mathrm{~cm} \times 5 \mathrm{~cm})$ as a substrate, which were glued on bricks (4 tiles on each brick). One brick was placed in each cage. In previous studies the applicability of these tiles as settling substrate for macroalgae has been proven successfully (Worm and Lotze 2006; Eriksson et al. 2009). Macroalgae were sampled at the end of the experiment, sorted under a dissecting microscope, determined to species level if possible, and dried at $80^{\circ} \mathrm{C}$ for at least $48 \mathrm{~h}$ to determine dry weight.

\section{Statistical analyses}

Grazer data was highly skewed and variances strongly heterogeneous also after strong transformations. We therefore analysed all data with Generalized Linear Mixed Models (GLMM). We used untransformed data in models with normally distributed error structures and log-link functions, after comparing models with different link functions for the best fit (log-likelihood). As explanatory variables, the model included the fixed main factors "predator" (closed vs. open) and "nutrients" (ambient vs. enriched), as well as the interaction between the predator and nutrient treatments, and the random factor "block". The block factor represents the spatial distribution of the cages in the field. Fisher's LSD post-hoc-tests were applied when significant interaction effects were found. Fucus 
bundles outside of each open cage $(N=10)$ were used to test for cage effects on grazers. Paired $t$-tests were adopted to pairwise compare grazers outside and inside of the open cages. No significant differences between the open cages and outside were found for amphipods, isopods, and gastropods (see Appendix for the statistics). Macroalgal biomass data was distributed bimodally with half of the values close to zero (ambient cages) and the other half 10-20 times higher (enriched cages). We therefore split the dataset and analysed ambient and enriched treatments separately applying GLMM as above. Stickleback densities were analysed following the same procedure as for the grazers.

In order to control for Type I error rates from the multiple testing in our data set, we Bonferroni corrected the significance levels to $\alpha=0.0167$ for grazer data and $\alpha=0.025$ for algal data. Quantity was tested three times in each grazer group (biomass, abundance, and mean individual size) and twice for macroalgae (one in ambient and one in enriched conditions).

\section{Results}

Overall, our results show that excluding larger predatory fish and adding nutrients together increased the abundance of meso-predator fish and simultaneously the biomass of filamentous macroalgae. Therefore, a trophic cascade from excluding larger predatory fish was only induced under elevated nutrient levels, through a meso-predator release and the reduction of palatable grazers (amphipods), which resulted in increased algal biomass.

The meso-predator stickleback strongly dominated the smaller bodied fish fauna. Stickleback abundances increased in the closed cages, but only when they were nutrient enriched (Fig. 1a; GLMM: interaction effect, $\left.\chi^{2}=7.25, P=0.007\right)$. During four snorkel samplings in late June and early July we counted $1.5 \pm 0.3$ (mean $\pm \mathrm{SE}, N=5$ ) stickleback inside the closed enriched cages which was 2.5 times more than in the open enriched cages (post-hoc LSD-test, $P=0.026$ ). After July, stickleback decreased strongly in abundance and vanished from the coastal zone (all counts in August were zero). Stickleback numbers in the ambient cages did not differ between the predator treatments.

The macroalgal community was dominated by three filamentous species: Cladophora glomerata, Pilayella littoralis and Ulva spp. Total macroalgal biomass was on average 15 times higher in the enriched cages $(0.328 \pm$ 0.093 , mean $\pm \mathrm{SE}, N=10$ ) than in the ambient cages $(0.022 \pm 0.007$, mean $\pm \mathrm{SE}, N=10)$. In the enriched cages the exclusion of large predatory fish induced a doubling in algal biomass (Fig. 1b; GLMM: $\chi^{2}=9.04$,
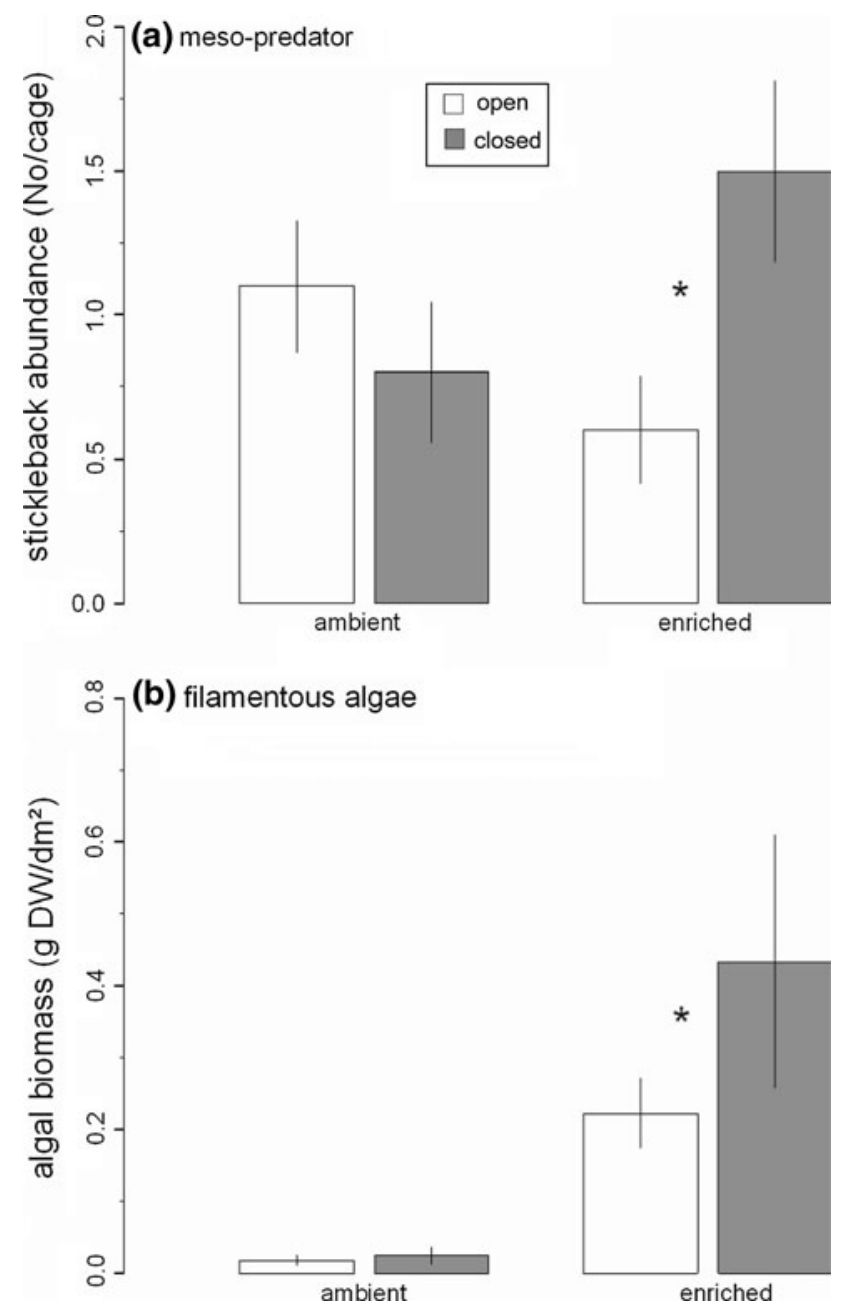

Fig. 1 Experimental effects on (a) stickleback (Gasterosteus aculeatus) abundance (means $\pm \mathrm{SE}, N=5$ ), and (b) total biomass of filamentous algae (means $\pm \mathrm{SE}, N=5$ ) in cages open (white bars) and closed (grey bars) for large predatory fish under ambient and enriched nutrient levels. a Stickleback numbers were significantly higher when excluding larger predatory fish under enriched conditions (GLMM: $\quad P=0.007$ ). * indicates a significant post-hoc result $(P=0.026)$. b Macroalgal biomass was significantly higher when excluding large predatory fish under enriched conditions. * indicate significant predator effects in separate GLMMs for enriched cages only (ambient: $P=0.03$, enriched: $P<0.003$ )

$P=0.003)$. In the ambient cages there was overall very low macroalgal biomass and no significant effect of the predator treatment was found (GLMM: $\chi^{2}=4.61, P=$ 0.031). Therefore, nutrient enrichment strongly increased algal biomass and predator exclusion generated together with nutrient enrichment a 23 times higher algal biomass (Fig. 1b). Thus, only under elevated nutrient levels exclusion of larger predatory fish induced a meso-predator release that cascaded down the food web to increase the production of filamentous algae indicative of an algal bloom.

Excluding larger predatory fish also affected the composition of invertebrate grazers. Mean amphipod biomass 
was reduced by more than half in the cages where large fish was excluded (Fig. 2a; Table 1). There was no significant interaction between the predator and the nutrient treatment, but a trend towards significance (Table $1 ; P=0.032$ ). Post-hoc tests revealed that this trend was due to predator effects only in the enriched cages (post-hoc LSD-tests on predator treatment: ambient: $P=0.619$, enriched: $P=0.019$ ). This may suggest that predator exclusion decreased amphipod biomass mainly under elevated nutrient levels, whereas predator effects were absent under ambient levels. Amphipods were significantly smaller when predators were excluded but when nutrients were added (Fig. 2b; Table 1; significant interaction effect, posthoc LSD-tests on predator treatment: ambient: $P=0.581$, enriched: $P=0.013$ ). Total amphipod abundance was not affected. Excluding large predatory fish reduced isopod abundance by $46 \%$, although differences were not statistically significant they showed a strong trend (Table 1; $P=0.019)$. Predator effects on isopods did not interact with the nutrient treatment. No effects on isopod biomass and mean individual weight were found (Fig. 2 c-d). Gastropod biomass, abundance, and mean individual weight were not significantly affected by any of the experimental treatments (Fig. 2e-f; Table 1). Thus, the exclusion of large predatory fish affected amphipods particularly under elevated nutrient conditions, resulting in an amphipod population with smaller individuals and half the total biomass. Isopod abundance decreased when large predators were absent, but did not interact with the nutrient treatment. The gastropod assemblages were not affected at all.

\section{Discussion}

This study shows that top-down control and trophic cascades in a coastal benthic food web depend on the functional composition of both predator and herbivore communities as well as on resource availability. Both predator and nutrient treatment interacted to increase the density of meso-predators, change the composition of invertebrate grazers, and increase the biomass of filamentous algae. First, we confirmed earlier results that the removal of larger predators generated a meso-predator release that increased the biomass of filamentous algae (Eriksson et al. 2009), but only under elevated nutrient levels. Second, we also demonstrated that effects of the meso-predator release of small-bodied fish (stickleback) propagated through the food web by shifting the composition of the grazer community towards an increased dominance of gastropod species by reducing amphipod biomass. Thus, we generated cascading effects, where predator declines caused an increased abundance of primary producers, only under elevated nutrient levels. Predator effects on isopods did not interact with the nutrient treatment. Therefore, the decrease in isopods could not be linked to the meso-predator release of stickleback as clearly as the decline in amphipods. The shift in size distribution towards smaller individuals of amphipod grazers indicates a key function of palatability towards the predator species. Together our results show convincingly that topdown control is an important factor for ecosystem structuring and that effects of predator declines on lower trophic levels depend strongly on species-specific relations both within and across trophic levels as well as on resource availability.

Eriksson et al. (2009) showed similarly to our experiment that predator exclusion changed the composition of invertebrates, which was mainly due to an increase in bivalves and a decrease in (small) gastropods. However, other grazers (e.g. amphipods, isopods), that are known to be important food sources for the used meso-predator were not affected by the predator treatment, and we believe that this was due to an inappropriate technique to sample the invertebrate community quantitatively. In contrast, the present study found that the presence/absence of large predatory fish mainly affected amphipods that are palatable to stickleback, which implies, that the grazer response to predation was determined by the palatability of the grazers to specific fish predator species. The palatability of the grazers in this study seemed strongly related to their functional traits. Amphipods possess an exoskeleton. Such chitinous structures enable the animals to develop and grow fast, but at the same time they are relatively fragile (particularly during and shortly after moulting) making them less resistant to predation. In contrast, the gastropods in this study are protected by a shell from calcium carbonate. As a result, gastropods usually grow slowly but possess a good protection against predation, and particularly Hydrobia and Theodoxus have a very thick shell. Furthermore, the actual prey size determines the palatability, so that especially large gastropods for instance may be inedible to most meso-predators. We therefore suggest that the effects of the meso-predators on the grazers were mainly determined by the prey's edibility towards the meso-predator. Duffy (2002) showed that palatability is an important mechanism linking diversity and ecosystem functioning, as diverse prey assemblages have a greater chance of containing less edible species. A meta-analysis by Hillebrand and Cardinale (2004) revealed that a more diverse prey assemblage is less vulnerable to consumption even across broad ranges of species diversity and different community types. This suggests that diversity effects on ecosystem processes may not be driven by species richness per se but rather by the functional diversity, for example the prey's edibility to their predators. Despite the fact that 
Fig. 2 Grazer biomass and individual biomass in cages open (white bars) and closed (grey bars) for large predatory fish under ambient and enriched nutrient levels. Biomass was calculated per 100 g Fucus DW (mean $\pm \mathrm{SE}, N=10$ ). Predator treatment showed significant main effects from GLMM for amphipod biomass $(P=0.002)$ as well as for amphipod size $(P=0.0003)$. There was a significant interaction effect for amphipod size $(P=0.005)$, and a statistical trend for amphipod biomass $(P=0.031)$ * indicate significant post-hoc results for the predator treatment under elevated nutrient levels $(P<0.02)$. No significant differences between the treatments on biomass or size were found for isopods and gastropods (a) amphipod biomass

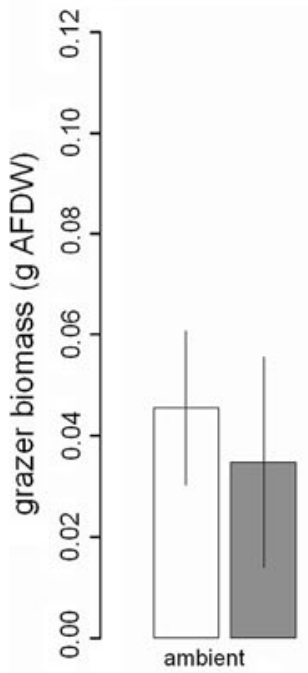

(c) isopod biomass
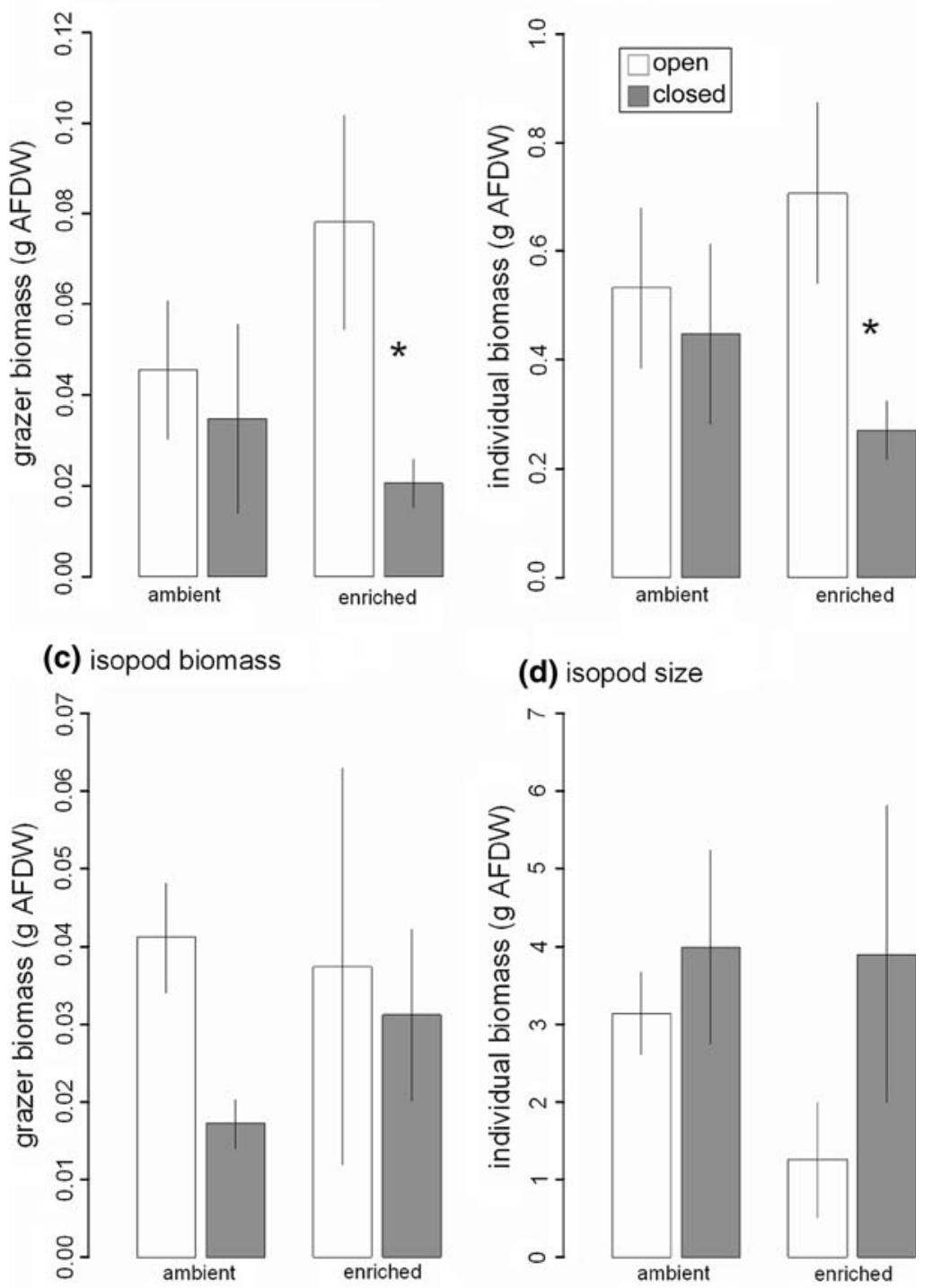

(b) amphipod size

(d) isopod size

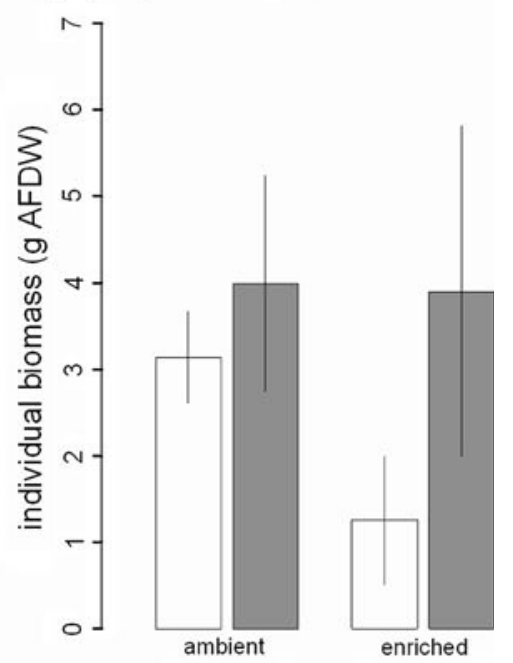

(e) gastropod biomass
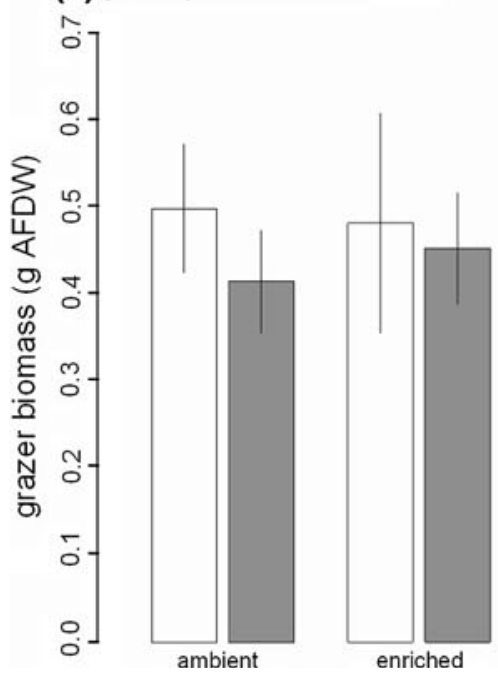

(f) gastropod size

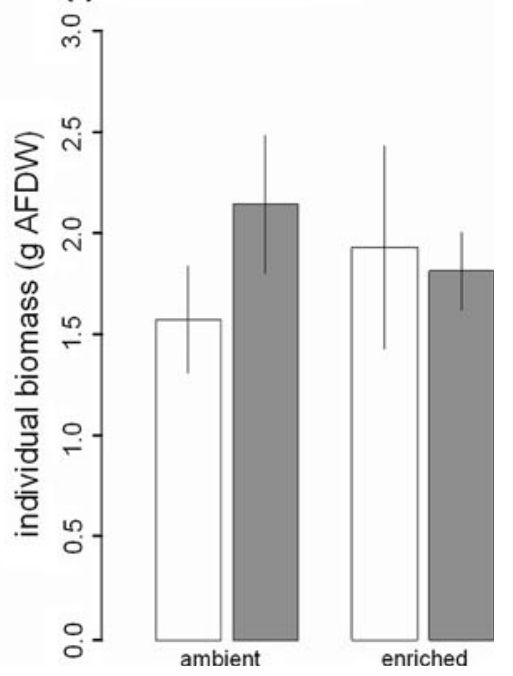


Table 1 Results from Generalized Linear Mixed Model on the predator exclosure and nutrient enrichment on grazer biomass, abundance and individual mean biomass (size)

\begin{tabular}{|c|c|c|c|c|c|c|c|}
\hline \multirow[t]{2}{*}{ Source of variation } & \multicolumn{3}{|c|}{ Biomass } & \multicolumn{2}{|c|}{ Abundance } & \multicolumn{2}{|l|}{ Size } \\
\hline & $d f$ & $\chi^{2}$ & $P$ & $\chi^{2}$ & $P$ & $\chi^{2}$ & $P$ \\
\hline \multicolumn{8}{|l|}{ Amphipods } \\
\hline Predator & 1 & 9.77 & 0.002 & 2.11 & 0.147 & 12.85 & 0.0003 \\
\hline Nutrients & 1 & 0.05 & 0.817 & 0.03 & 0.864 & 1.23 & 0.268 \\
\hline Predator $\times$ nutrients & 1 & 4.61 & 0.032 & 2.23 & 0.136 & 7.74 & 0.005 \\
\hline Block & 4 & 8.11 & 0.088 & 15.0 & 0.005 & 30.67 & $<0.0001$ \\
\hline \multicolumn{8}{|l|}{ Isopods } \\
\hline Predator & 1 & 2.47 & 0.116 & 5.51 & 0.019 & 4.49 & 0.034 \\
\hline Nutrients & 1 & 2.98 & 0.084 & 2.06 & 0.151 & 3.25 & 0.071 \\
\hline Predator $\times$ nutrients & 1 & 0.002 & 0.964 & 0.18 & 0.676 & 2.77 & 0.096 \\
\hline Block & 4 & 11.25 & 0.024 & 6.17 & 0.187 & 9.67 & 0.046 \\
\hline \multicolumn{8}{|l|}{ Gastropods } \\
\hline Predator & 1 & 0.96 & 0.327 & 2.74 & 0.098 & 0.82 & 0.366 \\
\hline Nutrients & 1 & 0.2 & 0.658 & 0.19 & 0.59 & 0.3 & 0.585 \\
\hline Predator $\times$ nutrients & 1 & 0.03 & 0.857 & 0.05 & 0.824 & 0.493 & 0.026 \\
\hline Block & 4 & 7.04 & 0.134 & 4.41 & 0.353 & 19.79 & 0.0006 \\
\hline
\end{tabular}

Bold numbers indicate statistically significant results $(P<0.025)$

the use of functional groups in food web studies is not a new approach (Tilman et al. 1997), most studies so far that have included functional diversity in assessments of trophic interactions have focused on primary producers and their responses to predation pressure (e.g. Duffy et al. 2001; Lotze et al. 2001). In contrast, studies, like ours, that focus on higher trophic levels are relatively under-represented in the literature (Downing 2005).

Greater meso-predator abundance induced at elevated nutrient levels a shift in grazer composition and simultaneously a greater biomass of filamentous algae. The shift in grazer composition towards gastropods suggests a trade-off between an efficient resource use and the grazers' resistance to predation. Grazers are able to dampen an enhanced growth of opportunistic algae from nutrient enrichment, but only in the absence of their predators (Korpinen et al. 2007). This effect is expected to be more pronounced when grazers are complementary in their feeding preferences (Råberg and Kautsky 2007b), which suggests a dependency of the grazers' response to both top-down and bottom-up effects on their functional diversity. The amphipods and isopods in this study have a short lifespan and fast reproductive rates (Kolding and Fenchel 1979; Salemaa 1979), which likely enables them to respond more rapidly to ecosystem changes ('dynamic grazers') than gastropod species ('static grazers', from Gruner et al. 2008). Therefore, amphipods and isopods are expected to benefit sooner from an increase in resource biomass following nutrient enrichment (Gruner et al. 2008). Moksnes et al. (2008) showed that elevated nutrient levels induced biomass accumulation in Gammarus, and similar effects were shown by Hemmi and Jormalainen (2002) for the isopod Idotea, and by Worm and Lotze (2006) for gastropods. Nutrient enrichment enhanced the effect of the predator exclusion on amphipods, which resulted in stronger reduction in amphipod biomass and their according mean individual biomass in the closed enriched cages, suggesting that resource availability may enhance top-down effects. Therefore, top-down and bottom-up forces together affected the grazer composition and both forces could not be regarded isolated. The interplay of both forces implies a trade-off between resistance to predation pressure and the ability to utilise the increased resources that may ultimately be reflected in the grazers' edibility (see Leibold 1989). Furthermore, changes in food web constellations could have mediated changes in interspecific competition between amphipods and isopods such as competing for the same resource or apparent competition (Frid and Marliave 2010) by sharing the same predator. Competition between the grazers could have potentially caused an artefact of the predator treatment, since perch can consume sticklebacks, but also feeds on isopods (pers. obs.), while stickleback prefers amphipods (pers. obs.). Thus, reduced biomass of amphipods in the closed cages could have also resulted from stronger competition from isopods in the absence of perch. However, isopod abundance also decreased in the closed cages. Thus, there is no support for increased grazer competition from changes in the fish composition.

Bottom-up effects on producers were stronger when large predators were removed. However, the overall very 
low algal biomass in the ambient cages might have hampered the ability to find statistically significant effects from predator exclusion without adding nutrients. The effect of enrichment on algal biomass might have also been diminished by the grazers since Russell and Connell (2007) could show that grazers reduced more biomass of algae that were exposed to higher nutrient levels, but only under oligotrophic background conditions. Still, the exclusion of large predators and nutrient enrichment positively interacted to increase the algal biomass by 23 times, implying that a decline of top-predators simultaneous to eutrophication may have multiplying effects on producers. Grazers were able to reduce a substantial part of the increased algal biomass from nutrient enrichment when large predators were present. In contrast, the meso-predator release increased algal biomass through the facilitation of gastropod grazers that are less efficient grazers on macroalgae. Joint effects of top-down and bottom-up forces in marine systems have been described across two trophic levels, where effects of nutrient enhancement on primary producers were stronger in the absence of predators (Burkepile and Hay 2006; Hereu et al. 2008). In this study, we found evidence for synergistic effects of top-down and bottom-up control even across four trophic levels. However, the experimental manipulations of both predators and nutrients were confounded. The number of stickleback around the cages depended not only on the predator treatment, but also on the nutrient treatment (Fig. 1a). Therefore, this experiment was basically a choice test for stickleback and invertebrate grazers where they could choose among the different treatments. Stickleback preferred cages that not only protected them from larger predators but that were also nutrient enriched. Nutrient enrichment of the water column can affect grazers' nutrient stoichiometry and increase grazer biomass (Liess and Hillebrand 2006; Spivak et al. 2009). Thus, foraging for more and higher nutritious prey in the enriched cages might explain higher stickleback densities, although nutrient effects on grazer biomass were very weak. In general, the results support theoretical models where consumers immigrate and emigrate actively between patches depending on resource availability (Oksanen et al. 1995; Nisbet et al. 1997). In these short-term population dynamic models, increased resource availability stimulates the production of primary biomass in patches with three trophic levels when consumers employ active dispersal and distribute freely (Nisbet et al. 1997).

Cage artefacts could have affected the behaviour of stickleback. Enhanced growth of periphyton on the cage structure and/or inside the cages due to the nutrient enrichment for instance could have attracted more small fish by providing shelter although cages have been brushed off regularly during the experiment. The drawbacks of predator exclosure experiments have been extensively described. For example, they may affect the natural distribution and abundance of predators due to the presence of the cage structure (Steele 1996), or partial cages may underestimate predation effects (Sih et al. 1985) because of the lower accessibility of the predators to the prey. The cage structure may have caused other biotic changes (e.g. lower abundances of phyto- and zooplankton) (Steele 1996) that were enhanced by the nutrient treatment, which may have affected the performance of the predator treatment. Therefore, general conclusions about the effects of predator exclusion and nutrient enrichment might be limited. However, both the grazer composition and the biomass of filamentous algae were affected by the interaction of both treatments. Hence, our results indicate synergistic effects of top-down and bottom-up forces where the effects of the excluding large predators were contingent on the resource availability and vice versa.

We conclude that declines in top-predators in combination with eutrophication may have dramatic impacts on lower trophic levels by generating cascading changes in the composition of grazers. In our study, a meso-predator release shifted the grazer community towards more predator-resistant species which were less able to counteract the enriched primary production. Significant differences in prey preferences between predators on the grazer community imply that food web changes from a decline in toppredators strongly depend on the species that are exploited and their functional traits. Thus, the functional composition both within and across trophic levels plays a crucial role in determining ecosystem vulnerability to anthropogenic impacts such as exploitation or eutrophication. Overfishing of piscivores can have similar effects on primary producers than eutrophication (Vasas et al. 2007). Therefore, both anthropogenic impacts can synergistically enhance the development of bloom-forming algae, resulting in the loss of ecosystem services, such as water quality and cultural services.

Acknowledgments We wish to thank S. Govella, H. van Steen, and $\mathrm{H}$. Reiss for help in the field and valuable comments on the experimental set up. Special thanks are due M. Bracken and three anonymous reviewers for comments that improved the manuscript. Thanks also to the staff at Askö Marine Laboratory for logistical assistance.

Open Access This article is distributed under the terms of the Creative Commons Attribution Noncommercial License which permits any noncommercial use, distribution, and reproduction in any medium, provided the original author(s) and source are credited.

\section{Appendix 1}

See Fig. 3. 


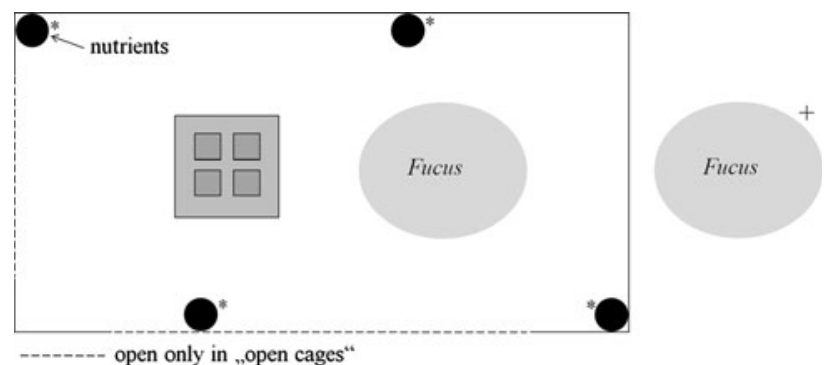

Fig. 3 Schematic drawing of the cages for predator exclosure experiment. The grey small quadrats represent the tiles that were glued on a brick for sampling macroalgae. Annotations: * only in enriched cages, ${ }^{+}$only together with open cages

\section{Appendix 2}

See Fig. 4.

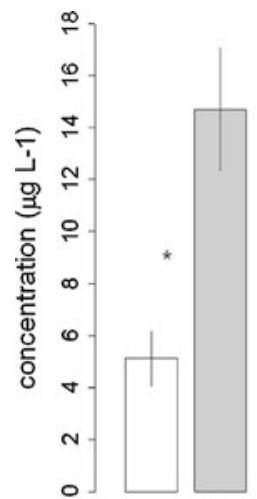

total $\mathrm{N}$

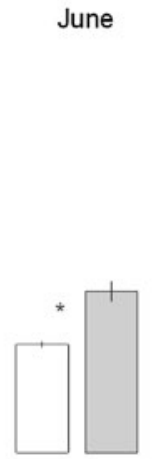

total P

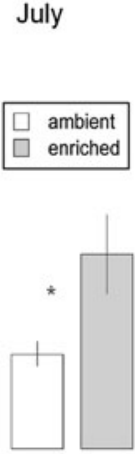

total $\mathrm{N}$

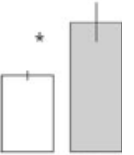

total P
Fig. 4 Nutrient concentrations in the water column inside the ambient (white bars) and enriched (grey bars) cages in June and July, respectively. Total nitrogen (total $N$ ) was assigned as the sum of $\mathrm{NH}_{4}{ }^{+}$and $\mathrm{NO}_{3}{ }^{-} / \mathrm{NO}_{2}{ }^{-}$. Total phosphorous (total $P$ ) was $\mathrm{PO}_{4}{ }^{3-}$. $*$ indicate significant ANOVA results $(P<0.05)$

\section{Appendix 3}

See Table 2.

Table 2 ANOVA results on nutrient concentrations in the water column with nutrient and predator treatment as fixed factors. Total nitrogen (total $N$ ) was assigned as the sum of $\mathrm{NH}_{4}{ }^{+}$and $\mathrm{NO}_{3}{ }^{-} / \mathrm{NO}_{2}{ }^{-}$

\begin{tabular}{|c|c|c|c|c|c|c|c|c|c|}
\hline & \multirow[t]{3}{*}{$d f$} & \multicolumn{4}{|l|}{ June } & \multicolumn{4}{|l|}{ July } \\
\hline & & \multicolumn{2}{|c|}{ Total $N$} & \multicolumn{2}{|c|}{ Total $P$} & \multicolumn{2}{|c|}{ Total $N$} & \multicolumn{2}{|c|}{ Total $P$} \\
\hline & & $F$ & $P$ & $F$ & $P$ & $F$ & $P$ & $F$ & $P$ \\
\hline Predator & 1 & 3.34 & 0.086 & 2.75 & 0.117 & 1.809 & 0.197 & 0.36 & 0.556 \\
\hline Nutrients & 1 & 15.22 & 0.0013 & 29.83 & 0.00005 & 6.67 & 0.02 & 6.38 & 0.023 \\
\hline $\begin{array}{r}\text { Predator } \times \\
\text { nutrients }\end{array}$ & 1 & 0.87 & 0.364 & 4.53 & 0.049 & 2.81 & 0.113 & 0.31 & 0.588 \\
\hline
\end{tabular}

$\overline{\text { Total phosphorous (total } P \text { ) was } \mathrm{PO}_{4}{ }^{3-} \text {. Nutrients were measured in June and }}$ July, respectively

Bold numbers indicate statistically significant results $(P<0.05)$

\section{Appendix 4}

See Table 3.

Table 3 Results of paired $t$ tests for cage artefacts on grazer biomass and individual biomass (size), square root transformed values were used

\begin{tabular}{llllll}
\hline Source of variation & & $\begin{array}{l}\text { Mean } \pm \text { SE } \\
(N=10)\end{array}$ & $d f$ & & $P$ \\
& & & & \\
\hline Gammarus biomass & In & $0.062 \pm 0.014$ & & & \\
& Out & $0.049 \pm 0.014$ & 9 & 0.491 & 0.635 \\
Gammarus abundance & In & $90.6 \pm 15.0$ & & & \\
& Out & $120.2 \pm 21.2$ & 9 & -1.243 & 0.245 \\
Gammarus size & In & $0.62 \pm 0.11$ & & & \\
& Out & $0.936 \pm 0.645$ & 9 & 0.078 & 0.94 \\
Isopod biomass & In & $0.039 \pm 0.013$ & & & \\
Isopod abundance & Out & $0.055 \pm 0.015$ & 9 & -1.041 & 0.325 \\
& In & $17.4 \pm 2.9$ & & & \\
Isopod size & Out & $24.9 \pm 4.9$ & 9 & -1.33 & 0.216 \\
& In & $2.194 \pm 0.538$ & & & \\
Gastropod biomass & Out & $2.39 \pm 0.674$ & 9 & -0.31 & 0.766 \\
& In & $0.485 \pm 0.07$ & & & \\
Gastropod abundance & Out & $0.459 \pm 0.072$ & 9 & 0.364 & 0.724 \\
& In & $329.5 \pm 56.3$ & & & \\
Gastropod size & Out & $264 \pm 44.7$ & 9 & 1.03 & 0.332 \\
& In & $1.813 \pm 0.293$ & & & \\
& Out & $1.772 \pm 0.094$ & 9 & -0.17 & 0.866 \\
\hline
\end{tabular}

According mean biomass (in g AFDW per $100 \mathrm{~g}$ Fucus DW) and size (in mg AFDW) are untransformed

\section{References}

Ådjers K, Andersson J, Appelberg M, Eschbaum R, Fricke R, Lappalainen A, Minde A, Ojaveer H, Pelczarski W, Repečka R (2006) Changing communities of Baltic coastal fish-executive summary: assessment of coastal fish in the Baltic Sea. HELCOM

Burkepile DE, Hay ME (2006) Herbivore vs. nutrient control of marine primary producers: context-dependent effects. Ecology 87:3128-3139

Carpenter SR, Kitchell JF, Hodgson JR (1985) Cascading trophic interactions and lake productivity. Bioscience 35:634-639

Downing AL (2005) Relative effects of species composition and richness on ecosystem properties in ponds. Ecology 86:701-715

Duffy JE (2002) Biodiversity and ecosystem function: the consumer connection. Oikos 99:201-219

Duffy JE, MacDonald KS, Rhode JM, Parker JD (2001) Grazer diversity, functional redundancy, and productivity in seagrass beds: an experimental test. Ecology 82:2417-2434

Eklöv P, Persson L (1995) Species-specific antipredator capacities and prey refuges: interactions between piscivorous perch (Perca fluviatilis) and juvenile perch and roach (Rutilus rutilus). Behav Ecol Sociobiol 37:169-178

Eriksson BK, Ljunggren L, Sandström A, Johansson G, Mattila J, Rubach A, Råberg S, Snickars M (2009) Declines in predatory fish promote bloom-forming macroalgae. Ecol Appl 19:19751988 
Estes JA, Tinker MT, Williams TM, Doak DF (1998) Killer whale predation on sea otters linking oceanic and nearshore ecosystems. Science 282:473-476

Frid A, Marliave J (2010) Predatory fishes affect trophic cascades and apparent competition in temperate reefs. Biol Lett 6:533-536

Granéli E, Wallström K, Larsson U, Granéli W, Elmgren R (1990) Nutrient limitation of primary production in the Baltic Sea area. Ambio 19:142-151

Gruner DS, Smith JE, Seabloom EW, Sandin SA, Ngai JT, Hillebrand H, Harpole WS, Elser JJ, Cleland EE, Bracken MES, Borer ET, Bolker BM (2008) A cross-system synthesis of consumer and nutrient resource control on producer biomass. Ecol Lett 11:740-755

Heithaus MR, Frid A, Wirsing AJ, Worm B (2008) Predicting ecological consequences of marine top predator declines. Trends Ecol Evol 23:202-210

Hemmi A, Jormalainen V (2002) Nutrient enhancement increases performance of a marine herbivore via quality of its food alga. Ecology 83:1052-1064

Hereu B, Zabala M, Sala E (2008) Multiple controls of community structure and dynamics in a sublittoral marine environment. Ecology 89:3423-3435

Hillebrand H, Cardinale BJ (2004) Consumer effects decline with prey diversity. Ecol Lett 7:192-201

Hillebrand H, Kahlert M (2001) Effect of grazing and nutrient supply on periphyton biomass and nutrient stoichiometry in habitats of different productivity. Limnol Oceanogr 46:1881-1898

Ibrahim AA, Huntingford FA (1989) Laboratory and field studies on diet choice in three-spined sticklebacks. Gasterosteus aculeatus L., in relation to profitability and visual features of prey. J Fish Biol 34:245-257

Kahl U, Radke RJ (2006) Habitat and food resource use of perch and roach in a deep mesotrophic reservoir: enough space to avoid competition? Ecol Freshw Fish 15:48-56

Kofoed LH (1975) The feeding biology of Hydrobia ventrosa (Montagu). I. The assimilation of different components of the food. J Exp Mar Bio Ecol 19:233-241

Kolding S, Fenchel TM (1979) Coexistence and life-cycle characteristics of 5 species of the amphipod species genus Gammarus. Oikos 33:323-327

Korpinen S, Jormalainen V, Honkanen T (2007) Bottom-up and cascading top-down control of macroalgae along a depth gradient. J Exp Mar Bio Ecol 343:52-63

Lappalainen A, Kangas P (1975) Littoral Benthos of the Northern Baltic Sea II. Interrelationships of wet, dry and ash-free dry weights of macrofauna in the Tvärminne Area. Int Revue der gesamten Hydrobiol und Hydrographie 60:297-312

Lappalainen A, Rask M, Koponen H, Vesala S (2001) Relative abundance, diet and growth of perch (Perca fluviatilis) and roach (Rutilus rutilus) at Tvärminne, northern Baltic Sea, in 1975 and 1997: responses to eutrophication? Boreal Environ Res 6:107-118

Leibold MA (1989) Resource edibility and the effects of predators and productivity on the outcome of trophic interactions. Am Nat 134:922-949

Liess A, Hillebrand H (2006) Role of nutrient supply in grazerperiphyton interactions: reciprocal influences of periphyton and grazer nutrient stoichiometry. J North Am Benthol Soc 25:632-642

Lotze HK, Worm B, Sommer U (2001) Strong bottom-up and topdown control of early life stages of macroalgae. Limnol Oceanogr 46:749-757

MacNeil C, Dick JT, Elwood RW (1997) The trophic ecology of freshwater Gammarus spp. (Crustacea: Amphipoda): problems and perspectives concerning the functional feeding group concept. Biol Rev Camb Philos Soc 72:349-364

Moksnes P-O, Gullström M, Tryman K, Baden S (2008) Trophic cascades in a temperate seagrass community. Oikos 117:763777

Myers RA, Worm B (2003) Rapid worldwide depletion of predatory fish communities. Nature 423:280-283

Nisbet RM, Diehl S, Wilson WG, Cooper SD, Donalson DD, Kratz K (1997) Primary-productivity gradients and short-term population dynamics in open systems. Ecol Monogr 67:535-553

Oksanen L, Fretwell SD, Arruda J, Niemela P (1981) Exploitation ecosystems in gradients of primary productivity. Am Nat 118:240-261

Oksanen T, Power ME, Oksanen L (1995) Ideal free habitat selection and consumer-resource dynamics. Am Nat 146:565

Orav-Kotta H, Kotta J (2003) Seasonal variations in the grazing of Gammarus oceanicus, Idotea baltica, and Palaemon adspersus on benthic macroalgae. Proc Estonian Acad Sci Biol Ecol 52:141

Pace ML, Cole JJ, Carpenter SR, Kitchell JF (1999) Trophic cascades revealed in diverse ecosystems. Trends Ecol Evol 14:483-488

Polis GA, Holt RD (1992) Intraguild predation: the dynamics of complex trophic interactions. Trends Ecol Evol 7:151-154

Råberg S, Kautsky L (2007a) A comparative biodiversity study of the associated fauna of perennial fucoids and filamentous algae. Estuar Coast Shelf Sci 73:249-258

Råberg S, Kautsky L (2007b) Consumers affect prey biomass and diversity through resource partitioning. Ecology 88:2468-2473

Russell BD, Connell SD (2007) Response of grazers to sudden nutrient pulses in oligotrophic versus eutrophic conditions. Mar Ecol Prog Ser 349:73-80

Sala E (2006) Top predators provide insurance against climate change. Trends Ecol Evol 21:479-480

Salemaa H (1979) Ecology of Idotea spp. (Isopoda) in the Northern Baltic. Ophelia 18:133-150

Sih A, Crowley P, McPeek M, Petranka J, Strohmeier K (1985) Predation, competition, and prey communities: a review of field experiments. Annu Rev Ecol Syst 16:269-311

Spivak AC, Canuel EA, Duffy JE, Richardson JP (2009) Nutrient enrichment and food web composition affect ecosystem metabolism in an experimental seagrass habitat. PLoS ONE 4:e7473

Stachowicz JJ, Bruno JF, Duffy JE (2007) Understanding the effects of marine biodiversity on communities and ecosystems. Annu Rev Ecol Evol Syst 38:739-766

Steele MA (1996) Effects of predators on reef fishes: separating cage artifacts from effects of predation. J Exp Mar Bio Ecol 198:249-267

Steiner CF (2001) The effects of prey heterogeneity and consumer identity on the limitation of trophic-level biomass. Ecology 82:2495-2506

Tilman D, Knops J, Wedin D, Reich P, Ritchie M, Siemann E (1997) The influence of functional diversity and composition on ecosystem processes. Science 277:1300-1302

Vasas V, Lancelot C, Rousseau V, Jordan F (2007) Eutrophication and overfishing in temperate nearshore pelagic food webs: a network perspective. Mar Ecol Prog Ser 336:1-14

Wikström SA, Kautsky L (2007) Structure and diversity of invertebrate communities in the presence and absence of canopyforming Fucus vesiculosus in the Baltic Sea. Estuar Coast Shelf Sci 72:168-176

Worm B, Lotze HK (2006) Effects of eutrophication, grazing, and algal blooms on rocky shores. Limnol Oceanogr 51:569-579

Worm B, Reusch TBH, Lotze HK (2000) In situ nutrient enrichment: methods for marine benthic ecology. Int Rev Hydrobiol 85:359-375 